\title{
The analysis of implementation options of transverse joints of bitumen sheets
}

\author{
Jan Plachý1,** \\ ${ }^{1}$ Institute of Technology and Business in České Budějovice, Department of Civil Engineering, \\ 370 01, České Budějovice, Czech Republic
}

\begin{abstract}
One of the most frequent sources of faults on flat roofs is a violation of the waterproof layers along the transverse joints between bitumen sheets. This fault is caused by a failure to adhere to the technological methodologies. This paper presents current solutions, as well as a new solution, for creating such joints. The new solutions are experimentally compared with existing solutions.
\end{abstract}

\section{Introduction}

Adhesive bitumen sheets (ABS) represents an up-to-date and sophisticated technology. ABS technology has huge advantages, as well as severe deficiencies. The advantages are [1]:

- its practical application,

- after application it is strictly prohibited to work with an open flame; the technology is therefore suitable for:

- waterproofing premises that are not at great risk of catching fire,

- connecting bitumen sheets to constructions without the need for welding (skylights, barrier glands),

- laying on polystyrene foam in comparison to assembled panels,

- the flatness with which the bitumen sheets can be laid thereby preventing unequal strain (welding overlaps),

- its economical application in terms of gas (welding torch) or electricity (hot-air welding).

The disadvantages are [1]:

- its application depends on climatic conditions,

- it is not possible to inspect the joints in detail (the bitumen cast is missing),

- it is not possible to guarantee that the transverse overlaps are fully waterproof; most ABS systems include gritting; the sheets must therefore be flame-welded or hot-air connected.

The subject of this article, as described in brief below, is part of ongoing in-depth research. The main goal of this article is to generate a transverse joint without the need for thermal treatment. Whereas the application of the majority of bitumen sheets requires thermal treatment, either flame welding or hot-air drying, to produce transverse joints, this does not apply to bitumen sheets without gritting. However, if the length of the applied

*Corresponding author: plachy@mail.vstecb.cz 
bitumen sheet is different from the adhesive bitumen sheet from the manufacturer, it remains necessary to apply proper thermal treatment. A number of viable options are put forward to tackle this crucial issue. These options are subsequently subjected to strength tests and compared to the traditional solutions.

\section{Material and methods of testing}

\subsection{Materials}

ABSs can be divided into several groups according to their exact composition. In practice, there are three common ABS compositions.

Both the upper and lower cover material consists of bitumen material of the same adhesiveness. These types of adhesive bitumen sheets are widely manufactured. In terms of production costs, lower quality polymers are usually preferred; high quality polymers are used sparingly. For this reason, the bitumen sheets are characterized by a lower adhesiveness at the base in contrast to other adhesive sheets. However, this type of bitumen sheets may be better when it comes to creating transverse joints because the upper and lower cover materials fuse better.

The upper cover material consists of common polymer-bitumen material; the lower cover material consists of a highly adhesive bitumen material. This type of adhesive bitumen sheet is produced by those manufacturers which have the capacity to apply two different kinds of material to the bearing batting at the same time. The application of the common polymer-bitumen material as the upper cover permits the application of highly adhesive bitumen material made from special polymers as the lower cover without the price of the product rising. In addition, the high adhesiveness of these products is preserved.

The upper cover material consists of common polymer-bitumen material; the lower cover material consists of common polymer-bitumen material covered by a thin and highly adhesive bitumen material. In order to produce this type of adhesive sheet, it is necessary to employ white-hot technology. With respect to cost, this option is the most effective. However, there are minor issues with regards to its production and the long-term functionality of the highly adhesive thin layer prior to application.

For the experimental part of this paper the following materials were selected:

1) ABSs with the upper and lower cover material consisting of the same highly adhesive bitumen material; the bearing batting PES + ST $250 \mathrm{~g} / \mathrm{m}^{2}$ with fine grain mineral gritting; flexibility at low temperatures according to ČSN EN 1109:2009 is $-15^{\circ} \mathrm{C}$;

2) Double-sided ABSs with heavily modified bitumen material;

3) Single-sided ABSs for sealing; with heavily modified bitumen material with external coating in the form of $\mathrm{Al}$ foil and geotextile.

\subsection{Methods of testing}

The peeling resistance of the formed transverse joints was tested in accordance with ČSN EN 12316-1 [2] (see Figure 1), as was the shearing resistance in accordance with ČSN EN 12317-1 [3] (see Figure 2). With respect to those ABSs with an upper external coating made of fine grain gritting, the size of the transverse joints was fixed at $100 \mathrm{~mm}$. 

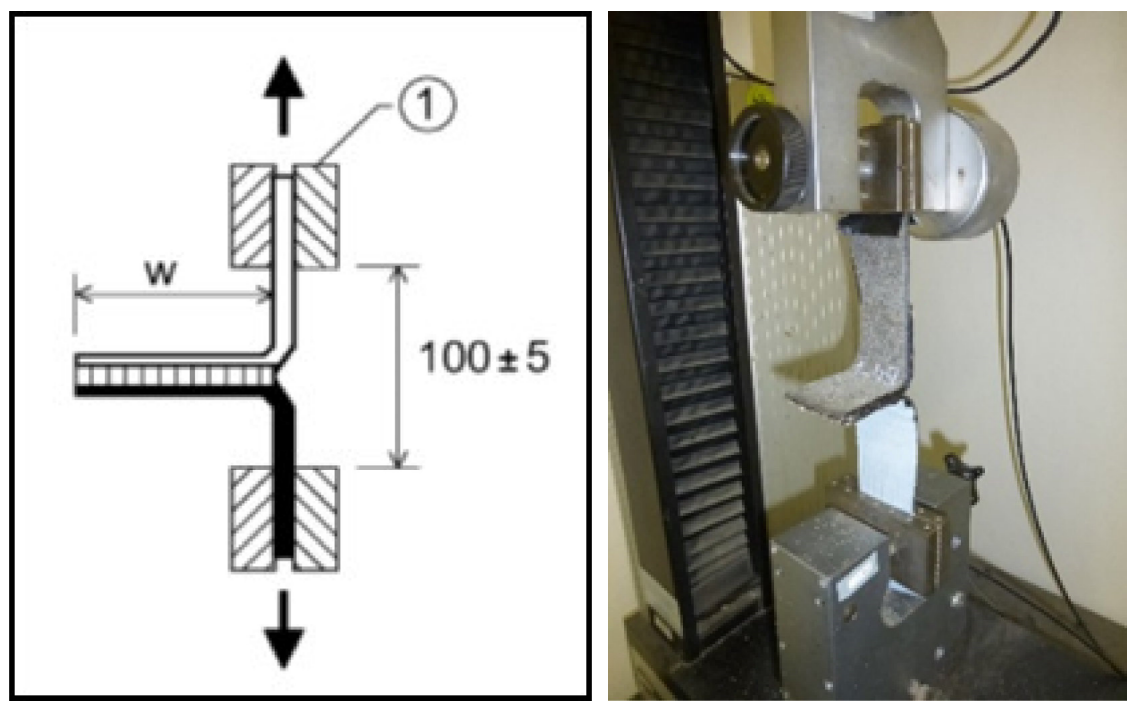

Fig. 1. Diagram of joint peeling resistance test in accordance with ČSN EN 12316-1. Source: author.
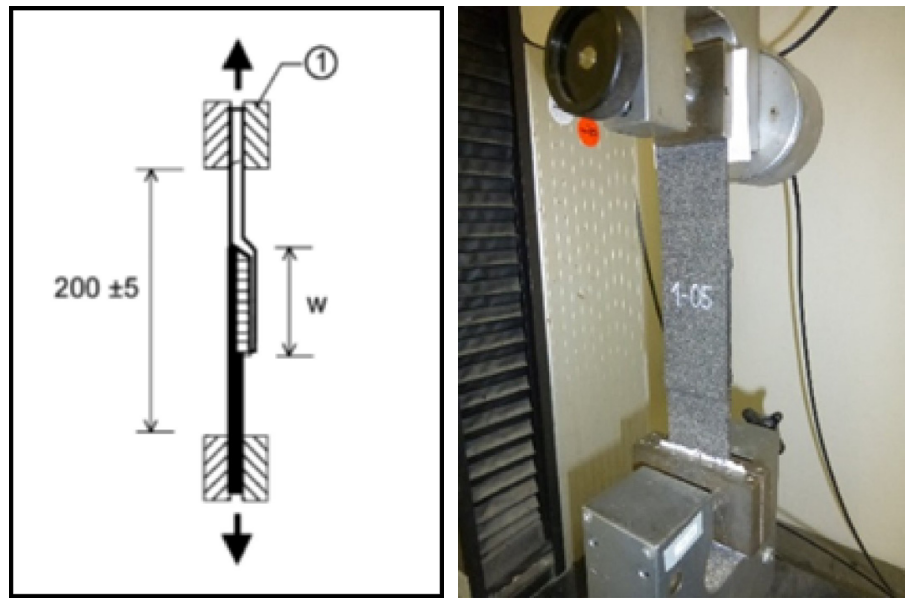

Fig. 2. Diagram of joint shearing resistance test in accordance with ČSN EN 12317-1. Source: author.

Two viable options for creating transverse joints were analysed:

1) Taping with double-sided ABSs of $75-100 \mathrm{~mm}$ width without ABS base adjustment. The ABS is firmly taped to the fine grain mineral gritting (see Figure 3);

2) Pushing the parts together and sealing it with an ABS of $100 \mathrm{~mm}$ width (see Figure 4).

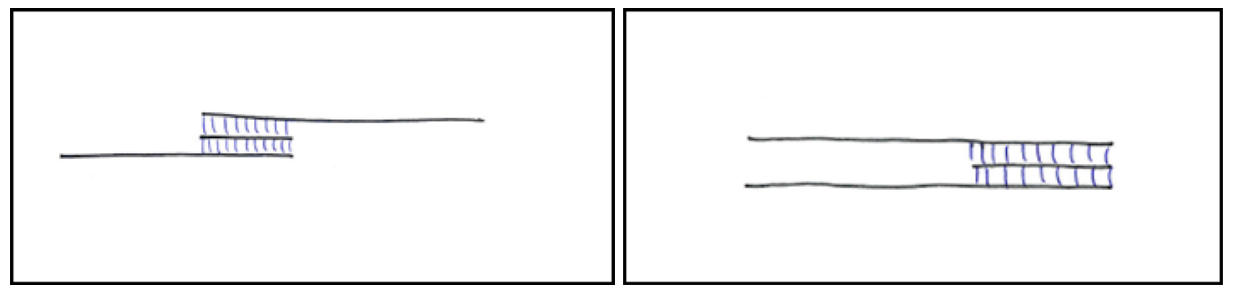

Fig. 3. ABS transverse joint taped with a double-sided adhesive bitumen sheet. Left - shearing resistance test sample; Right - peeling resistance test sample. Source: author. 

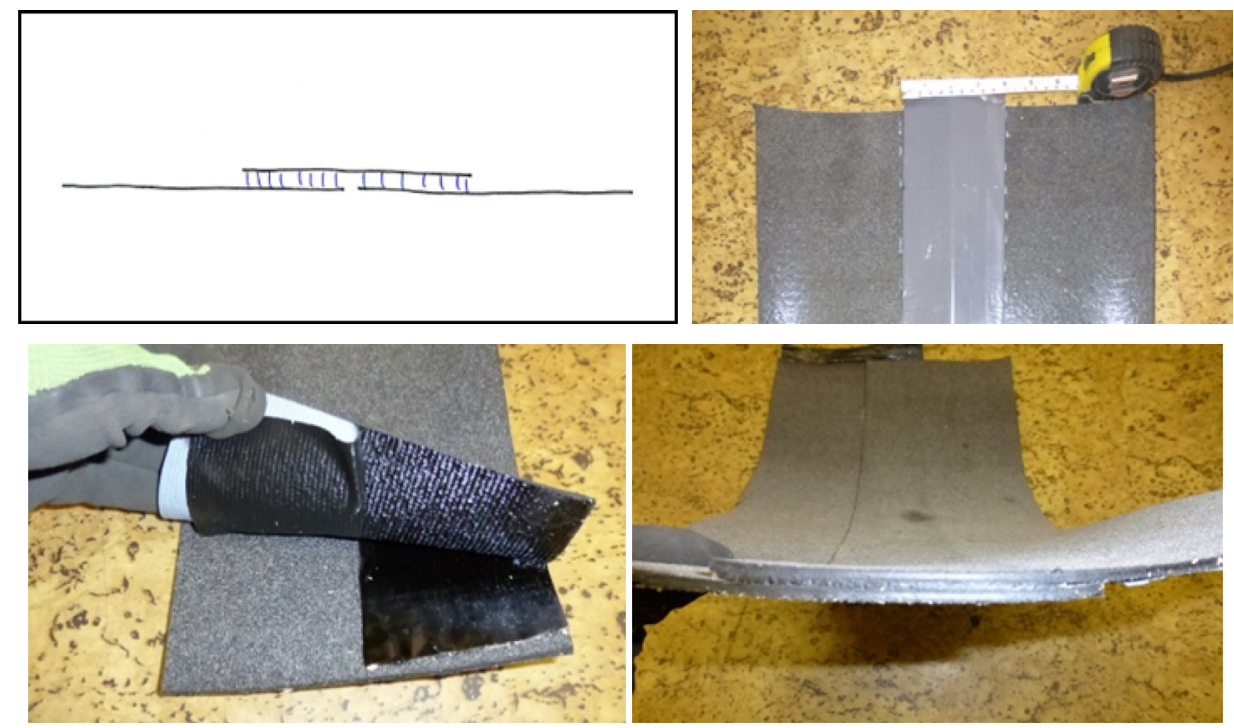

Fig. 4. ABS transverse joint created by pushing the parts together and sealing it with an ABS. Shearing force testing sample. Source: author.

The results of the strength tests according to [2] and [3] were compared to the strength of those joints created using thermal treatment i.e. flame welding (see Figure 5) and hot-air welding (see Figure 6).

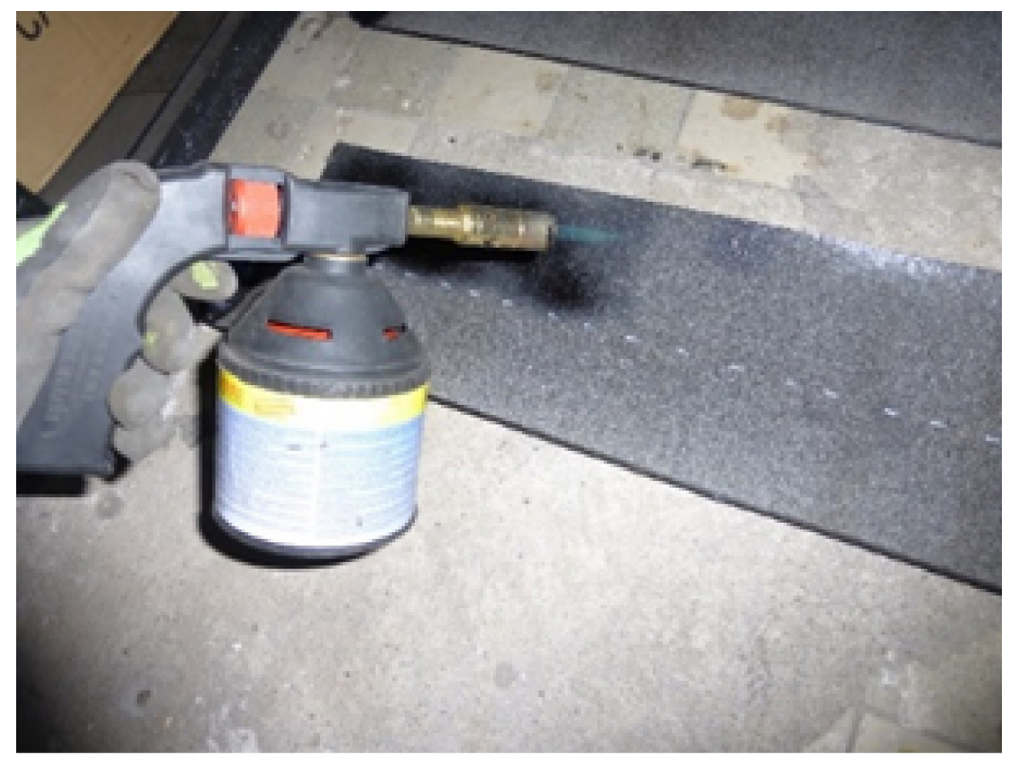

Fig. 5. Creation of transverse joints of $100 \mathrm{~mm}$ width by flame welding. Source: author. 


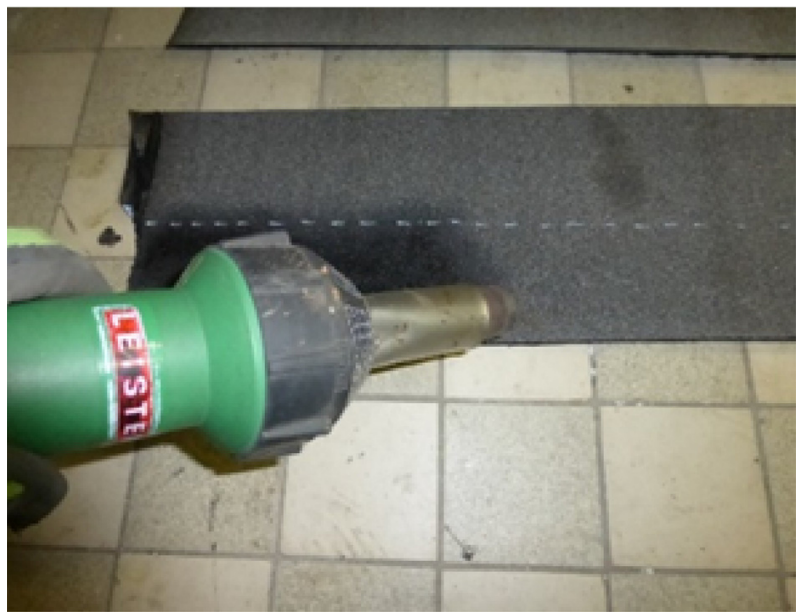

Fig. 6. Creation of transverse joints of $100 \mathrm{~mm}$ width by hot-air welding. Source: author.

\section{Results}

The transverse joints were tested for their adherence to the tensile strength of the ABS which was determined as $734 \mathrm{~N} / 50 \mathrm{~mm}$. The joints created by welding achieved $81-87 \%$ of the ABS tensile strength. The joints created using double-sided ABS achieved approximately $65 \%$ of the ABS tensile strength. The joints sealed with ABS achieved $14 \%$ of the ABS tensile strength.

Table 1. Test results for the shearing resistance and peeling resistance of transverse joints.

\begin{tabular}{|c|c|c|c|}
\hline Transverse seal (front) & $\begin{array}{c}\text { Tensile } \\
\text { strength } \\
{[\mathbf{N} / 50 \text { mm] }}\end{array}$ & $\begin{array}{c}\text { Shear } \\
\text { resistance of } \\
\text { joints } \\
{[\mathbf{N} / 50 \text { mm] }}\end{array}$ & $\begin{array}{c}\text { Peel resistance } \\
\text { at the joints } \\
\text { [N/50 mm] }\end{array}$ \\
\hline Standard & EN 12311-1 & EN 12317-1 & EN 12316-1 \\
\hline Reinforced bitumen sheets [N/50 mm] & 734 & 0 & o \\
\hline $\begin{array}{c}\text { Joint design width of } 100 \text { mm by melting by } \\
\text { fire }\end{array}$ & 0 & 639 & 31 \\
\hline $\begin{array}{c}\text { Bonding width of } 100 \text { mm by melting using } \\
\text { hot air }\end{array}$ & 0 & 597 & 15 \\
\hline $\begin{array}{c}\text { Bonding with double-sided adhesive tape in } \\
\text { width of } 75 \text { mm }\end{array}$ & 0 & 482 & 21 \\
\hline $\begin{array}{c}\text { Bonding with double-sided adhesive tape in } \\
\text { width of } 100 \text { mm }\end{array}$ & 0 & 102 & 0 \\
\hline $\begin{array}{c}\text { Performing connections to the event and strip } \\
\text { bound with tape in widths of } 100 \mathrm{~mm}\end{array}$ & 0 & 475 & 44 \\
\hline
\end{tabular}




\section{Discussion}

\subsection{Determination of shear resistance of joints}

After a typical procedure (immersion coating), the joint strength did not achieve the required ABS tensile strength; there was a tolerance of approximately $10 \%$ tolerance in the average value for both operating procedures (flame welding, hot-air welding).

With respect to sheet strength, the joint strength after taping with double-sided ABS was insufficient; however, if the absolute value increases to $500 \mathrm{~N} / 50 \mathrm{~mm}$ this is considered sufficient. It is also necessary to take into consideration that the joints were created at a temperature of $15^{\circ} \mathrm{C}$. As a result, in practice it is not only necessary to apply the appropriate downward force, but also to maintain a steady temperature, which must not rise above $15^{\circ} \mathrm{C}$

The joint strength after sealing achieved only $14 \%$ of the ABS tensile strength. The strength of this type of joint is determined by the strength of the bearing batting - AL foil or geotextile. The joint not only proved insufficient with regards to the strength tests, but also as a $\mathrm{T}$ joint.

The results must be added to the high-grammage bearing batting with great strength, the complete testing samples implementation and, above all, bitumen material temperature (flexibility at temperature $-15^{\circ} \mathrm{C}$ )

In order to determine whether the joint with the double-sided tape met requirements, it was put through a waterproof test [4]. The results show that it indeed met the requirements for roofing i.e. $10 \mathrm{kPa}$. The joint sealed with adhesive tape (pushed together method) was not put through a waterproof test.

\subsection{Determination of peel resistance of joints}

The peeling resistance test generated low strength values for all the joints. The results were therefore not comparable with the results of the ABS strength tests. The results are only comparable with the different methods for creating transverse joints. The joint strength of the joint created with double-sided ABSs amounted to $30-45 \%$. Although the resistance value is not high, it is considered sufficient. This type of joint must have a value of $150 \mathrm{~N} / 50 \mathrm{~mm}$. The actual value was $20 \%$ higher.

A similar series of tests needs to be carried out with a larger number of samples than is suggested in [2] in order to eliminate the human factor (in terms of the preparation of the samples).

\section{Conclusion}

The experimental tests show that it is possible to create transverse joints without the need of thermal treatment. Adhesive bitumen sheets offer an effective solution. However, this solution applies only to the base ABS; whereby the upper welded bitumen sheet seals the waterproofing layers.

\section{References}

1. J. Plachý, Střechy 2015: sborník př́spěvků (2015)

2. ČSN EN 12316-1, Flexible sheets for waterproofing - Part 1: Bitumen sheets for roof waterproofing - Determination of peel resistance of joints (2000) 
3. ČSN EN12317-1, Flexible sheets for waterproofing - Part 1: Bitumen sheets for roof waterproofing - Determination of shear resistance of joints (2000)

4. ČSN EN 1928, Flexible sheets for waterproofing - Bitumen, plastic and rubber sheets for roof waterproofing - Determination of watertightness (2001) 